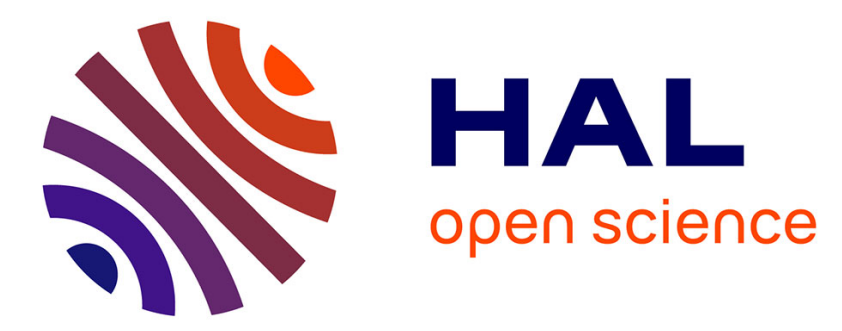

\title{
The design and calibration of a versatile PIXE/RBS facility
}

\author{
P.F. Hinrichsen, A. Houdayer, G. Kajrys, A. Belhadfa
}

\section{To cite this version:}

P.F. Hinrichsen, A. Houdayer, G. Kajrys, A. Belhadfa. The design and calibration of a versatile PIXE/RBS facility. Revue de Physique Appliquée, 1988, 23 (9), pp.1557-1564. 10.1051/rphysap:019880023090155700 . jpa-00245984

\section{HAL Id: jpa-00245984 https://hal.science/jpa-00245984}

Submitted on 1 Jan 1988

HAL is a multi-disciplinary open access archive for the deposit and dissemination of scientific research documents, whether they are published or not. The documents may come from teaching and research institutions in France or abroad, or from public or private research centers.
L'archive ouverte pluridisciplinaire HAL, est destinée au dépôt et à la diffusion de documents scientifiques de niveau recherche, publiés ou non, émanant des établissements d'enseignement et de recherche français ou étrangers, des laboratoires publics ou privés. 
Classification

Physics Abstracts

06.90

\title{
The design and calibration of a versatile PIXE/RBS facility
}

\author{
P. F. Hinrichsen $(*)$, A. Houdayer (**), G. Kajrys and A. Belhadfa \\ Laboratoire de Physique Nucléaire, Université de Montréal, C.P. 6128, Succursale « A », Montréal, Québec \\ H3C 3J7, Canada
}

(Reçu le 21 décembre 1987, révisé le 25 avril 1988, accepté le 2 juin 1988)

\begin{abstract}
Résumé. - Le développement et les performances d'un montage PIXE (proton induced X-ray emission) sont décrits pour l'analyse quantitative des éléments traces. L'ensemble a été conçu en vue d'une sensibilité et d'une fiabilité accrues ainsi que pour l'analyse de routine d'un grand nombre d'échantillons à un coût minimal. Un système de pulsations électrostatiques du faisceau a été développé dans le but de diminuer le temps mort et les empilements inévitables avec les constantes de temps nécessaires à l'obtention d'une très haute résolution. Des précautions spéciales ont été prises pour minimiser toutes les sources de bruit de fond. La procédure de calibration du montage est aussi décrite.
\end{abstract}

Abstract. - The design and performance of a PIXE (Proton Induced X-ray Emission) facility for trace element analysis is presented, with emphasis on those features which enhance the throughput and sensitivity. An on demand pulse pileup rejection system reduces the spectral distortion and increases the data collection rate. Special precautions are taken to minimize all sources of background and the calibration procedure is described.

\section{Introduction.}

The combination of the excitation of X-rays by protons, or other charged particles (PIXE), and their detection with a $\mathrm{Si}(\mathrm{Li})$ detector constitutes a well established and rapid method of multi-element analysis, with sensitivity down to the ppm level [1, 2]. Since only milligram quantities of sample and minimal target preparation are required PIXE is ideally suited to rapid survey or monitoring of many samples [3-5]. Once the apparatus is calibrated, absolute concentrations can be obtained for elements present at the ppm level. To exploit these advantages the apparatus should require a minimum of setup time, be designed for maximum throughput and provide on-line data analysis. The system must allow optimization of the sensitivity for specific elements by variation of the beam energy and particle type, and the use of selective X-ray absorbers. In order to extract reliable quantitative data the beam energy,

$\left(^{*}\right)$ On leave from John Abbott College, St. Anne de Bellevue, Quebec H9X 3L9, Canada.

$(* *)$ On leave from CEGEP André-Laurandeau, Montreal, Quebec H8N 2J4, Canada. the beam charge, and the detector response must be reproducible.

If the ultimate sensitivity of the technique is to be exploited then clean laboratory facilities for target preparation, for evaporating conducting layers, or for adding known quantities of a reference element for internal calibration, must be available.

For samples which are very thin compared with the proton range and absorption length for the $\mathrm{X}$ rays, i.e. less than $1 \mathrm{mg} / \mathrm{cm}^{2}$, quantitative results can be rapidly extracted from the X-ray spectra in terms of an empirical calibration of the system, using thin targets of known composition [6,7]. However, for targets in which the incident particles loose a significant amount of energy, corrections for the variation of cross-section with energy as the particle penetrates the target, for absorption of the emitted X-rays as they leave the target, and for fluorescence of the target material by the primary X-rays, are required. These corrections are usually made by assuming an approximate composition and then iterating the concentrations of the major constituents until the results converge to a self consistent fit to the data. Fortunately a number of computer codes which take these and other corrections into account now exist 
[8-12], and have been shown to give consistent results when processing the same data [13].

The PIXE facility should be seen within the context of a range of techniques available for materials analysis at the University of Montreal Accelerator Laboratory including high energy implantation, ERD (Elastic Recoil Detection), PIGE (Particle Induced Gamma Emission) and channeling, as well as a focused proton beam of $20 \mu$ diameter [14] for PIXE/RBS studies.

\section{Experimental setup.}

The Tandem accelerator produces a stable proton beam of up to $100 \mathrm{nA}$ on target with the energy variable between $1.0 \mathrm{MeV}$ and $12 \mathrm{MeV}$. The beam line and target chamber are shown in figure 1 . The electrostatic deflector plates (not shown) and first slit form part of a beam pulse pileup rejection system [15-19].

There are two sets of graphite beam defining apertures in the chamber. The first is $4 \mathrm{~mm}$ diameter, followed by a $5 \mathrm{~mm}$ diameter anti-scatter slit, and is used with macroscopically non-uniform targets. A second set of graphite apertures of $2 \mathrm{~mm}$ and $3 \mathrm{~mm}$ diameter respectively are used for uniform, and for thick targets i.e. of target thickness greater than the range of the protons. We have also obtained beam currents of up to $5 \mathrm{nA}$ through a final aperture of $200 \mu \mathrm{m}$ diameter.

For routine measurements up to 80 targets can be loaded into a modified Kodak carousel which is used as a target changer. A beam shutter is activated during target changing. A $150 \mathrm{l} / \mathrm{s}$ turbo-molecular pump provides pumpdown times of less than $10 \mathrm{~min}$ and an $800 \mathrm{l} / \mathrm{s}$ oil diffusion pump and cold trap maintain the vacuum, which is usually limited to $5 \times 10^{-6}$ Torr by the outgassing and vapour pressure of the targets.

For fragile targets, or when the target position or angle are to be varied, a 12 target ladder which is introduced via an air lock is used. This target ladder can also be mounted on an HPT 040 micromanipulator [20] so that specific spots on the target can be analysed. A TV camera serves to monitor the state of the targets, and to display the target identification. A surface barrier detector at $170^{\circ}$ is used for RBS measurements [2], which are made simultaneously with the PIXE. For thin targets the beam current is measured by a Faraday cup. For measurements on thick targets, or when the electron

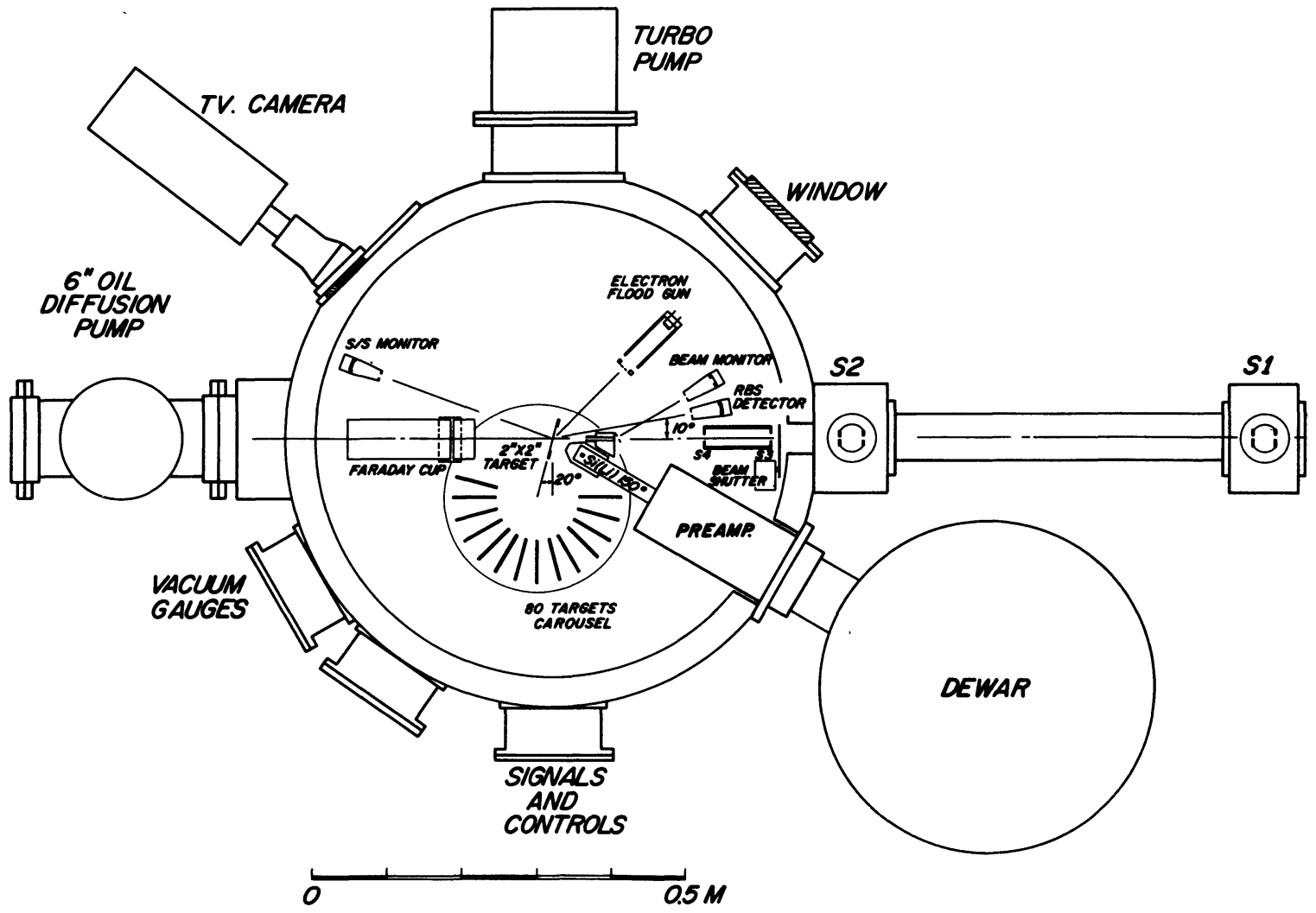

Fig. 1. - Diagram of the beam line and PIXE scattering chamber showing : a) the beam collimators, b) the Faraday cup and the elastic scattering beam monitor used with thick targets, c) the electron flood gun, d) the modified 80 slide Kodak carousel target changer, e) the collimated $\mathrm{Si}(\mathrm{Li}) \mathrm{X}$-ray detector which is at $150^{\circ}$ and $50 \mathrm{~mm}$ from the target and $\mathrm{f}$ ) the RBS surface barrier detector. 
flood gun is in use, the beam current is monitored by a second surface barrier detector which detects the backscattered particles from a gold plated vane, which periodically interrupts the beam.

For insulating targets a major increase in the bremsstrahlung background arises from charging of the target due to secondary emission [21-28]. This can be eliminated by : depositing a conducting layer on the surface of the target [23], mixing a conductor with the target material [26], running under poor vacuum [21], using a transverse magnetic field [24], discharging the target with an electron flood gun [21] or with secondary electrons from a foil placed in the beam just in front of the target [25]. We have chosen to use a $400 \mathrm{~V}$ electron flood gun, and have found that, after an initial burn in period of a few minutes for a new filament, there is no detectable contamination of the targets from the tungsten filament.

2.1 X-RAY Detector. - The Ortec Si(Li) X-ray detector is $4 \mathrm{~mm}$ in diameter and $4 \mathrm{~mm}$ thick, with a $200 \AA$ gold layer and a $0.1 \mu \mathrm{m}$ silicon dead layer and is behind a $12.7 \mu$ thick beryllium window. It has an energy resolution of $\mathrm{FWHM}=153 \mathrm{eV}$ at $5.9 \mathrm{keV}$. The $22 \mathrm{~mm}$ diameter cryostat allows the front face of the detector to be placed $50 \mathrm{~mm}$ from the center of the target, and at an angle of $150^{\circ}$ to the beam which reduces the bremsstrahlung background [29], and has the added advantage that a thinner absorber can be used to prevent backscattered protons from entering the $\mathrm{Si}(\mathrm{Li})$ detector. A nylon collimator shields the detector from X-rays produced in the beam defining apertures and also serves to hold the $\mathrm{X}$-ray absorbers. The chamber has extra ports which can be used for a second $\mathrm{Si}(\mathrm{Li})$ detector, or for a $\mathrm{Ge}(\mathrm{Li})$ detector for PIGE.

2.2 Pileup ReJECtion. - The long pulse shaping time constants used for optimum energy resolution with $\mathrm{Si}(\mathrm{Li}) \mathrm{X}$-ray detectors require a time interval of about $80 \mu \mathrm{s}$ for the pulse to return to the baseline. This sets a limit of a few hundred counts per second on the counting rate if spectrum distortion due to pileup is not to limit the sensitivity. Electronic pileup rejection circuits are available, but they introduce a counting rate dependent deadtime. In many experiments, expecially with thick targets, pileup limits the data acquisition rate, and constitutes a severe constraint on the throughput of samples.

Beam pulse pileup rejection was first suggested by Jaklevic [15], and has been applied to PIXE by a number of groups [16-19]. When an X-ray pulse occurs in the $\mathrm{Si}(\mathrm{Li})$ detector, the proton beam is immediately turned off for the duration of the X-ray pulse, thus ensuring that no additional X-rays are generated during the processing time. The advantages are : a) the system is non-paralysable, b) no deadtime corrections are required, and c) the target is only irradiated while the $\mathrm{Si}(\mathrm{Li})$ detector is live, thus target heating and radiation damage is reduced to a minimum. This is especially important for volatile targets, biological samples, and for channelling studies.

The performance of on demand pileup rejection systems is limited by the minimum number of protons which arrive at the target after an X-ray pulse is detected. This depends on the system risetime and on the transit time of the beam from the deflection system to the target. The tradeoff between fast risetime and minimum transit time requires that the deflection system be located close to the target. Both the risetime and the falltime of the pulse should be short, relative to its duration, to avoid Xray generation during the switching times, and to reduce the power dissipation in the tube at high counting rates.

Our beam pulsing system is shown in figure 2 and was adapted from a system previously used for nuclear lifetime measurements [30]. An Ortec 579

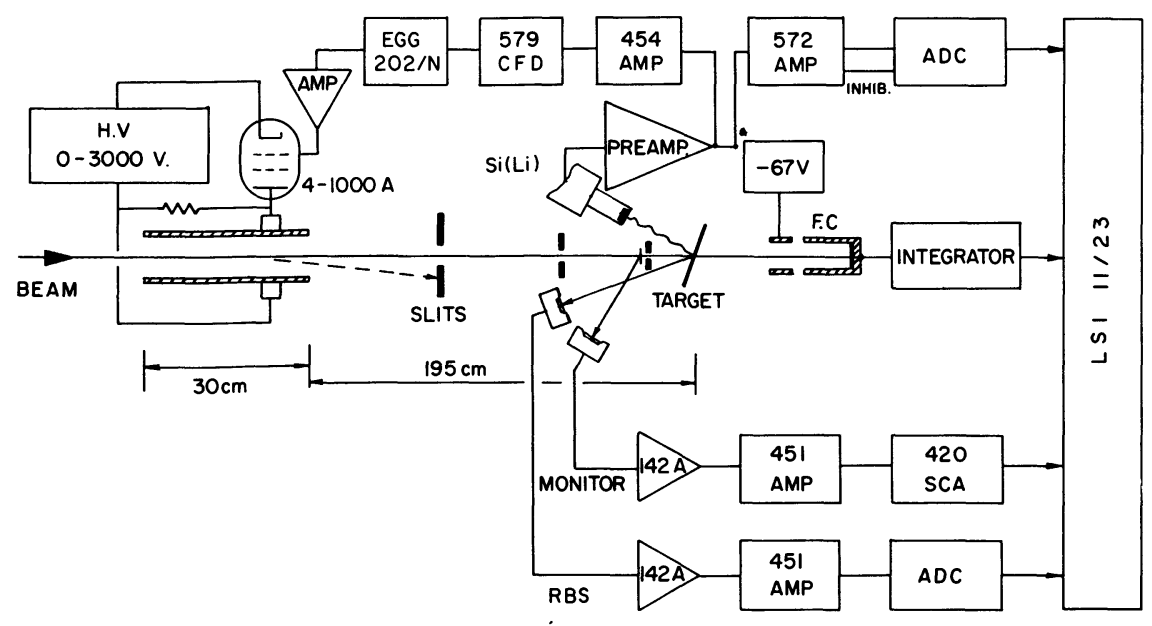

Fig. 2. - The beam pulse pileup rejection system, and associated electronics. 
fast filter amplifier shapes the pulse from the preamplifier before it triggers an Ortec 584 fast discriminator the output of which drives an EG \& G 101 shaper. The duration of the resulting square pulse can be varied from $1 \mu \mathrm{s}$ to $1 \mathrm{~ms}$, to suit the linear amplifier shaping time constants. This pulse drives the grid of a $4000 \mathrm{~A}$ tetrode via a HV transistor. For $1.0 \mathrm{MeV}$ protons the pileup at a counting rate of $4000 \mathrm{cps}$ is reduced by a factor of about 30 .

2.3 SENSITIVITY. - The ultimate sensitivity for the detection of a particular trace element, within a given irradiation time, depends on the signal to background ratio and the counting rate. The X-ray signal depends on the ionization cross-section, the fluorescence yield, X-ray absorption in the target, the detection efficiency, the full energy response and the solid angle of the detector. In the absence of interfering lines such as $\mathrm{L}$ and $\mathrm{M} \mathrm{X}$-rays from high $Z$ impurities, the background is primarily due to electron and particle bremsstrahlung, with contributions due to Compton scattered gamma-rays from nuclear reactions in the beam collimators, and X-rays produced by scattered particles hitting the vacuum chamber. The latter two sources of background were reduced by appropriate shielding and collimation of the detector. For targets containing materials of higher $Z$ than the impurities of interest, another source of background is the tailing of the detector response, caused by incomplete charge collection $[13,31]$.

Detailed consideration of these factors [1] show that almost optimal data can be obtained for a wide range of $Z$ by choosing two bombarding energies. $1.0 \mathrm{MeV}$ is ideal for the region $Z=11$ to 26 (the response of our detector is limited to $Z>10$ by the beryllium window). For the higher mass region we use a $37.7 \mathrm{mg} / \mathrm{sq} \mathrm{cm}$ thick kapton absorber in front of the detector and $E_{\mathrm{p}}=3.0 \mathrm{MeV}$, for which the $\mathrm{L}$ $\mathrm{X}$-ray cross-sections from high $Z$ elements are large, while the gamma-ray background is still small. As compared with a single exposure with a « funny filter », the use of two bombarding energies has the advantage of providing a consistency check, and often helps in elucidating the intensities of overlapping peaks.

\section{Calibration and data analysis.}

The «Guelph Pixe Fitting Code» developed by Campbell et al. [13] is used for the analysis of spectra from both thick and thin targets. This program uses a top hat filtering technique [32] to remove the smooth background from the spectrum, and then a nonlinear least squares routine fits the peak heights and widths to Gaussians and calculates their areas.
Given the initial proton energy, the target thickness, geometry, and matrix composition, the program uses theoretical ionization cross-sections, X-ray fluorescence yields, attenuation coefficients, and proton range energy data to evaluate the X-ray yields from up to 26 trace elements simultaneously.

For the analysis of thick target PIXE spectra the composition of the target matrix is required, and for many targets the primary constituents are low $Z$ elements which are not observed in the PIXE data. The concentrations of the low $Z$ elements can be derived from the RBS spectra which are analysed using the code RUMP [33]. For the analysis of semithick targets (targets of thickness less than the particle range but thick enough that energy loss and $\mathrm{X}$-ray attenuation cannot be neglected, i.e. more than $1 \mathrm{mg} / \mathrm{cm}^{2}$ ) the GUELPH program requires estimates of the incident and emergent particle energies, and these can also be conveniently deduced from the RBS spectra. Even for thin targets the RBS spectra provide a useful consistency check, and serve to identify any changes in the target backing.

The PIXE system was calibrated in terms of the counts in the $K_{\alpha 1}$ peak for elements with $Z \geqslant 28$ and the unresolved $\mathrm{K}_{\alpha 1+\alpha 2}$ peak for elements with $Z<28$. A set of calibrated thin targets, obtained from Micromatter Inc. [34], were bombarded with $1 \mathrm{MeV}$ and $3 \mathrm{MeV}$ protons to obtain the absolute yields in counts per microcoulomb of protons per $\mu \mathrm{g} / \mathrm{cm}^{2}$ for each target element. In addition solutions containing $1000 \mathrm{ppm}$ of two or more elements were mixed, deposited on thin formvar backings and freeze dried. They were then bombarded with $3 \mathrm{MeV}$ protons to obtain relative yields for eleven elements which were not readily available as calibrated thin targets. The resulting yield curves, which for ease of comparison have been renormalized to include the $\mathrm{K}_{\alpha 2}$ fraction for elements with $Z \geqslant 28$, are shown in figure 3 together with the theoretical yield curves which have been calculated relative to $\mathrm{Cu}$, taking into account the fluorescence yields and absorption corrections. The agreement at $3 \mathrm{MeV}$ is excellent. At $1 \mathrm{MeV}$ there are sizable differences, especially for $\mathrm{Na}, \mathrm{Mg}$ and $\mathrm{Al}$, and subsequent servicing of the detector showed that these were due the formation of a thin layer of ice on the detector surface [35].

In order to check the accuracy of the thick target analysis when using the thin target calibration data a number of pure thick targets were analysed. The average of the concentrations determined by the program for 12 mono-elemental targets bombarded at $1 \mathrm{MeV}$ and 10 at $3 \mathrm{MeV}$ were $99 \pm 7 \%$ and $98 \pm 6 \%$ respectively. In addition several thick targets of biological standards [36] and of geological standards have been bombarded at 1 and $3 \mathrm{MeV}$. The results for the three geological standards BEN, MRG and SY2 have been presented elsewhere [37]. 


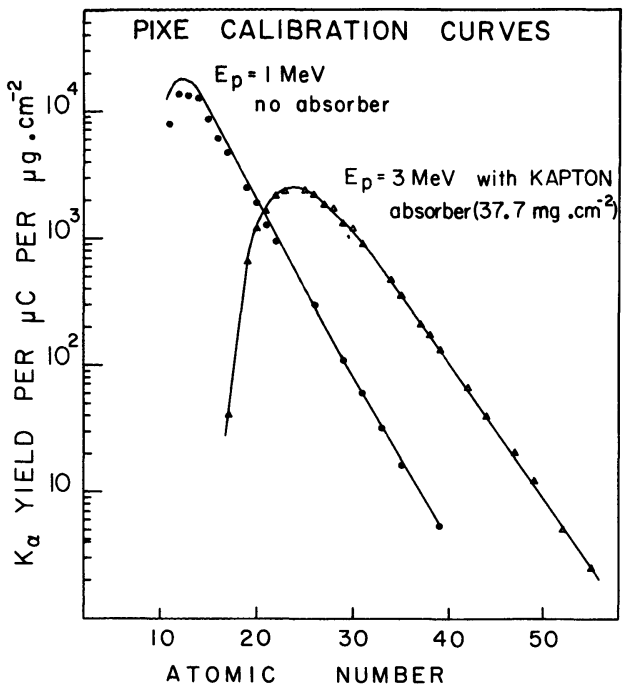

Fig. 3. - The absolute calibration of the system in $\mathrm{K}_{\alpha 1+\alpha 2}$ counts/microcoulomb per $\mu \mathrm{g} / \mathrm{cm}^{2}$, at proton energies of 1.0 and $3.0 \mathrm{MeV}$. The data is for a $4 \mathrm{~mm}$ diameter by $4 \mathrm{~mm}$ thick $\mathrm{Si}(\mathrm{Li})$ detector at $50 \mathrm{~mm}$ from the target. The $3.0 \mathrm{MeV}$ data includes the $\mathrm{X}$-ray attenuation of the $37.7 \mathrm{mg} / \mathrm{sq} \mathrm{cm}$ kapton absorber. The solid points are derived from measurements on calibrated targets [34], while relative measurements are represented by open points. The solid curves are derived from theoretical crosssections corrected for absorption and the detector efficien$\mathrm{cy}$, and normalized at $\mathrm{Cu}$.

The results for two marine sediments, MESS-1 and BCSS-1 [38], and for NBS standard Orchard leaves and Bovine liver are presented in figure 4 and table I. The overall agreement with the quoted concentrations is good. The BCSS-1 sample was not heated prior to bombardment which may account for the high concentrations of $\mathrm{S}$ and $\mathrm{Cl}$. The concentration of $\mathrm{Ti}$ in marine sediments was occasionally anomalously large. Some high values for $\mathrm{Si}$ were found in the biological samples. For typical bombardments the statistics were insufficient for the program to reliably analyse the As $\mathrm{K}$ lines in the presence of the $\mathrm{Pb} \mathrm{L}$ lines, so the As results were eliminated from the fit.

\section{Conclusion and acknowledgments.}

A rapid throughput PIXE system, that is capable of handling both thin and thick targets has been calibrated and is in routine use for accurate trace element concentration determinations at the ppm
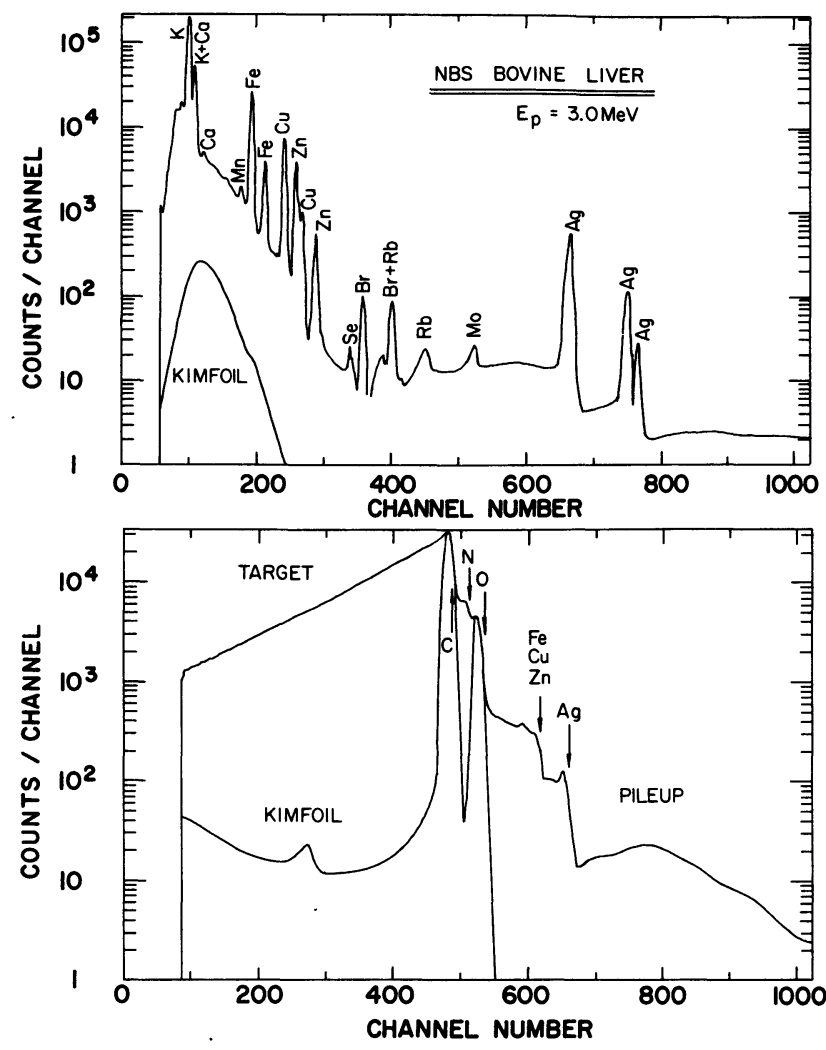

Fig. 4. - X-ray and RBS spectra from a target of NBS standard Bovine Liver on a Kimfol backing. The spectra from a Kimfol backing are also shown for comparison. The major constituents of the target material can be identified in the RBS spectrum, and the detailed elemental concentrations derived from the $\mathrm{X}$-ray spectrum are in good agreement with the NBS values.

level. The combination of PIXE for the trace elements with simultaneous RBS to determine the target thickness and the low $Z$ constituents of the target matrix has proved to be a very versatile and reliable technique.

We wish to thank the Natural Sciences and Engineering Research Council of Canada for financial support, IREQ for some of the equipment, and FCAR for release time (P.F.H. and A.H.). Our thanks are due to Dr. J. L. Campbell for many helpful discussions and for making his PIXE analysis program available, to J. Mishkin for help with the data analysis, and to Dr. H. A. Van Rinsvelt for supplying the NBS standard samples. We owe a special debt of gratitude to Jacques and Pierre Berichon for solving many of our technical problems. 
Table I. - Thick target PIXE results, at $E_{\mathrm{p}}=1$ and $3 \mathrm{MeV}$, for four reference materials. The certified values are from references [36, 38], with uncertified values in parentheses. $3000 \mathrm{ppm}$ of $\mathrm{Ag}$ have been added to the Orchard leaves and Bovine Liver samples. The concentrations are in ppm unless otherwise specified.

\begin{tabular}{|c|c|c|c|c|c|c|}
\hline \multirow{2}{*}{ Element } & \multicolumn{3}{|c|}{ Marine Standard MESS-1 } & \multicolumn{3}{|c|}{ Marine Standard BCSS-1 } \\
\hline & Composition & $1 \mathrm{MeV}$ Data & $3 \mathrm{MeV}$ Data & Composition & $1 \mathrm{MeV}$ Data & $3 \mathrm{MeV}$ Data \\
\hline $\mathrm{Na}$ & $1.85 \%$ & $2.41(10) \%$ & & $2.0 \%$ & 2.2 (1) \% & \\
\hline $\mathrm{Mg}$ & $0.87 \%$ & $1.10(5) \%$ & & $1.47 \%$ & 1.74 (5) \% & \\
\hline $\mathrm{Al}$ & $5.84 \%$ & $7.21(15) \%$ & & $6.26 \%$ & $7.6 \quad$ (2) \% & \\
\hline $\mathrm{Si}$ & $31.6 \%$ & $29.7(5) \%$ & & $30.9 \%$ & $29.9(6) \%$ & \\
\hline $\mathbf{P}$ & 640 & $890(250)$ & & 670 & $740(250)$ & \\
\hline$S$ & $0.72 \%$ & 0.63 (4) \% & & $0.36 \%$ & 0.74 (4) \% & \\
\hline $\mathrm{Cl}$ & $0.82 \%$ & $1.20(6) \%$ & & $1.12 \%$ & $1.86(7) \%$ & \\
\hline K & $1.86 \%$ & 2.3 (1) \% & 2.07 (2) \% & $1.8 \%$ & 2.3 (1) $\%$ & 2.09 (2) \% \\
\hline $\mathrm{Ca}$ & $0.48 \%$ & $0.60(6) \%$ & 0.54 (1) \% & $0.54 \%$ & $0.78(7) \%$ & 0.70 (1) \% \\
\hline $\mathrm{Sc}$ & $(20)$ & & & $(20)$ & & \\
\hline $\mathrm{Ti}$ & $0.54 \%$ & $0.60(4) \%$ & 0.50 (1) \% & $0.44 \%$ & $0.57(8) \%$ & 0.49 (1) \% \\
\hline $\mathrm{V}$ & 72 & & & 93 & & \\
\hline $\mathrm{Cr}$ & 71 & & $78(8)$ & 123 & & $160(8)$ \\
\hline $\mathrm{Mn}$ & 513 & $720(200)$ & 460 (13) & 229 & 377 (200) & $250(8)$ \\
\hline $\mathrm{Fe}$ & $3.05 \%$ & $3.8(4) \%$ & $3.30(3) \%$ & $3.29 \%$ & 4.2 (4)\% & 3.75 (4) \% \\
\hline $\mathrm{Co}$ & 10.8 & & & 11.4 & & \\
\hline $\mathrm{Ni}$ & 29 & & 27 (4) & 55 & & $55(5)$ \\
\hline $\mathrm{Cu}$ & 25 & & $25(5)$ & 18 & & $10(3)$ \\
\hline $\mathrm{Zn}$ & 191 & & $190(28)$ & 119 & & $115(5)$ \\
\hline $\mathrm{Ga}$ & 20 & & $15(4)$ & 23 & & $18(2)$ \\
\hline $\mathrm{Ge}$ & (1.7) & & & $(1.5)$ & & \\
\hline As & 11 & & & 11 & & \\
\hline $\mathrm{Se}$ & $(0.4)$ & & & $(0.4)$ & & \\
\hline $\mathrm{Br}$ & (200) & & $55(15)$ & (210) & & $120(6)$ \\
\hline $\mathrm{Rb}$ & (100) & & $150(5)$ & $(80)$ & & 140 \\
\hline $\mathrm{Sr}$ & (89) & & $110(10)$ & (96) & & $130(10)$ \\
\hline $\mathrm{Y}$ & (35) & & $50(10)$ & (50) & & \\
\hline $\mathrm{Zr}$ & (500) & & $240(40)$ & (350) & & 190 (17) \\
\hline $\mathrm{Nb}$ & (20) & & $34(4)$ & (14) & & $16(8)$ \\
\hline $\mathrm{Ag}$ & & & & & & \\
\hline $\mathrm{Pb}$ & 34 & & $36(6)$ & 22.7 & & $32(8)$ \\
\hline
\end{tabular}

\section{References}

[1] Johansson, S. A. E. and Johansson, T. B., Nucl. Instrum. Methods 137 (1976) 473.

[2] Michell, I. V. and Ziegler, J. F., Ion Beam Handbook for Materials Analysis, Eds. J. W. Mayer and E. Rimini (Academic Press Inc. New York) 1977, chapter 5.

[3] Lecomte, R. et al., Nucl. Instrum. Methods 150 (1978) 289.

[4] Hertel, N., Nucl. Instrum. Methods B 14 (1986) 58, and private commun.

[5] Ming-ChIEN, Li et al., Nucl. Instrum. Methods 181 (1981) 37.
[6] Johansson, G. I., Pallon, J., Malmovist, K. G. and AKelsson, K. R., Nucl. Instrum. Methods 181 (1981) 81.

[7] Borbely-Kiss, I. et al., Nucl. Instrum. Methods B 12 (1985) 496.

[8] Van Espen, P., Nullens, H., Adams, F., Microbeam Analysis, Ed. D. E. Newbury (San Francisco Press, San Francisco) 1979, p. 265.

[9] Kaufmann, H. C., Akelsson, R. K. and CourTENAY, W. J., Nucl. Instrum. Methods 142 (1977) 251. 
Table I (continued).

\begin{tabular}{|c|c|c|c|c|c|c|}
\hline \multirow{2}{*}{ Element } & \multicolumn{3}{|c|}{ NBS Standard Orchard Leaves } & \multicolumn{3}{|c|}{ NBS Standard Bovine Liver } \\
\hline & Composition & $1 \mathrm{MeV}$ Data & $3 \mathrm{MeV}$ Data & Composition & $1 \mathrm{MeV}$ Data & $3 \mathrm{MeV}$ Data \\
\hline $\mathrm{Na}$ & 82 & $310(40)$ & & $0.24 \%$ & $0.24(1) \%$ & \\
\hline $\mathrm{Mg}$ & $0.62 \%$ & 0.49 (1) \% & & $(605)$ & $517(10)$ & \\
\hline $\mathrm{Al}$ & & & & & & \\
\hline $\mathrm{Si}$ & $(0.048 \%)$ & 0.18 (1) \% & & & $202(6)$ & \\
\hline $\mathbf{P}$ & $0.21 \%$ & 0.18 (1) \% & & $1.1 \%$ & $1.10(1) \%$ & \\
\hline $\mathrm{S}$ & $(0.19 \%)$ & 0.19 (1) \% & & $0.8 \%$ & $0.79(1) \%$ & \\
\hline $\mathrm{Cl}$ & $(690)$ & $753(22)$ & & $(0.26 \%)$ & 0.25 (1) \% & \\
\hline $\mathrm{K}$ & $1.47 \%$ & 1.40 (1) \% & $1.40(2) \%$ & $0.97 \%$ & $0.92(1) \%$ & $1.02(5) \%$ \\
\hline $\mathrm{Ca}$ & $2.09 \%$ & 1.73 (1) \% & $2.23(2) \%$ & $(123)$ & $137(8)$ & $157(20)$ \\
\hline Sc & & & & & & \\
\hline $\mathrm{Ti}$ & & & & & & \\
\hline V & & & & & & \\
\hline $\mathrm{Cr}$ & 2.6 & & & & & \\
\hline $\mathrm{Mn}$ & 91 & & $100(13)$ & 10 & & $13(2)$ \\
\hline $\mathrm{Fe}$ & 300 & $380(38)$ & $306(40)$ & 270 & $347(30)$ & 338 (17) \\
\hline Co & $(0.2)$ & & & $(0.18)$ & & \\
\hline $\mathrm{Ni}$ & 1.3 & & & & & \\
\hline $\mathrm{Cu}$ & 12 & & $12(2)$ & 193 & & $240(14)$ \\
\hline $\mathrm{Zn}$ & 25 & & $29(5)$ & 130 & & $153(11)$ \\
\hline $\mathrm{Ga}$ & & & & & & \\
\hline $\mathrm{Ge}$ & & & & & & \\
\hline As & 10 & & & $(0.06)$ & & \\
\hline $\begin{array}{l}\mathrm{Se} \\
\mathrm{Br}\end{array}$ & (10) & & 7 (3) & 1.1 & & $6(3)$ \\
\hline $\mathrm{Rb}$ & 12 & & $13(5)$ & 18 & & $23(6)$ \\
\hline $\mathrm{Sr}$ & (37) & & $35(5)$ & $(0.14)$ & & \\
\hline $\mathrm{Y}$ & & & & & & \\
\hline $\mathrm{Zr}$ & & & & & & \\
\hline $\mathrm{Nb}$ & & & & & & 2110 \\
\hline $\begin{array}{l}\mathrm{Ag} \\
\mathrm{Pb}\end{array}$ & $\begin{array}{c}3000 \\
45\end{array}$ & & $\begin{array}{r}3038(30) \\
89(15)\end{array}$ & $\begin{array}{l}3000 \\
0.34\end{array}$ & & \\
\hline & & & & & & \\
\hline
\end{tabular}

[10] Hasslemann, I. et al., Nucl. Instrum. Methods 142 (1973) 163.

[11] Maxwell, J. A., Leigh, R. G., Campbell, J. L. and PAul, H., Nucl. Instrum. Methods $\mathbf{B}$ (1984) 301.

[12] Clayton, E., Nucl. Instrum. Methods 218 (1983) 221.

[13] Campbell, J. L. et al., Nucl. Instrum. Methods B 14 (1986) 204.

[14] Hinrichsen, P. F., Houdayer, A., Kajrys, G., Belhadfa, A. and Crine, J. P., Proc. 1st Int. Conf. on Nuclear Microprobe Technology (Oxford) September 1987, Nucl. Instrum. Methods B 30 (1988) 276.

[15] Jaklevic, J. M., Goulding, F. S. and LANDis, D. A., IEEE Trans. Nucl. Sci. NS-19 (1972) 392.

[16] Thibeau, H., Stadel, J., Cline, W. and Cahill, T. A., Nucl. Instrum. Methods 111 (1973) 615.
[17] Koenig, W., Richter, F. W., Steiner, U., Stock, R., ThielmanN, R. and Watjen, U., Nucl. Instrum. Methods 142 (1977) 225.

[18] Mingay, D. W., Jonker, W. D. and SMITH, B. J., PIXE-PURC, Rep. PEL-259, AEB Pelindaba (Pretoria, SA).

[19] Malmovist, K. G., Karlsson, E. and Akselsson, K. R., Nucl. Instrum. Methods 192 (1982) 523.

[20] Vacuum Generators Ltd, Menzies Rd., Hastings, Sussex TN341YQ, UK.

[21] Ahlberg, M., Johansson, G. and MalmQvist, K., Nucl. Instrum. Methods 131 (1975) 377.

[22] Tawara, H., Ishit, K. and Morita, S., Nucl. Instrum. Methods 132 (1976) 503.

[23] Papper, C. S., Chaudhri, M. A. and Rouse, J. L., Nucl. Instrum. Methods 154 (1978) 219.

[24] Mingay, D. W. and Barnard, E., Nucl. Instrum. Methods 157 (1978) 537. 
[25] Chaudhri, M. A. and Crawford, A., Nucl. Instrum. Methods 181 (1981) 31.

[26] Campbell, J. L. et al., Nucl. Instrum. Methods 181 (1981) 285.

[27] VAN Zon, J. B. A. D., KIVITS, H. P. M and VAN DER HEIDE, Nucl. Instrum. Methods 187 (1981) 569.

[28] Varier, K. M., NayaK, A. K. and Mehta, G. K., Nucl. Instrum. Methods B 10/11 (1985) 671.

[29] Folkmann, F., Cramon, K. M. and Hertel, N., Nucl. Instrum. Methods B 3 (1984) 11.

[30] HAMEL, L. A., Ph. D. Thesis University of Montreal (1985).

[31] Lowe, B. G., Advances in $\mathrm{Si}(\mathrm{Li})$ detectors (Link Systems Ltd., Halifax Rd., High Wycomb, Bucks HP12 3SE, UK).

[32] McCarthy, J. J. and Schamber, F. H., Proc. of the Workshop on Energy Dispersive X-Ray Spec- trometry (April 1979) NBS Special Publication 604.

[33] Doolittle, L. R., Nucl. Instrum. Methods B 9 (1985) 344.

[34] Heagney, L. M. and Heagney, J. S., Nucl. Instrum. Methods 167 (1979) 137.

[35] CoHEN, D. D., Nucl. Instrum. Methods 178 (1980) 481.

[36] NBS Certificate of Analysis, National Bureau of Standards, Washington DC, USA.

[37] Brissaud, I., HoudAYER, A. and HinRICHSEN, P. F., Radioanal, J., Nucl. Chem. Lett. 117 (1987) 99.

[38] Marine Analytical Standards Program, National Research Council of Canada, Chemistry Division, Ottawa, Canada. 